Vegueta. Anuario de la Facultad de Geografía e Historia

21 (1), 2021, 13-30

eISSN: 2341-1112

https://doi.org/10.51349/veg.2021.1.01

\title{
Paisajes culturales construidos para cultivar y habitar: retos hacia su sostenibilidad
}

\section{Cultural Landscapes Built to Cultivate and Inhabit: Challenges towards their Sustainability}

\author{
Lidia Esther Romero Martín \\ Universidad de Las Palmas de Gran Canaria \\ Instituto de Oceanografía y cambio Global \\ https://orcid.org/0000-0003-0846-4806 \\ lidia.romero@ulpgc.es \\ Juan Manuel Parreño Castellano \\ Universidad de Las Palmas de Gran Canaria \\ Departamento de Geografía \\ https://orcid.org/0000-0002-1082-456X \\ juan.parreno@ulpgc.es \\ María Angélica Salas \\ University of Coventry \\ Center for Agroecology, Water and Resilience \\ https://orcid.org/0000-0003-4295-397X \\ mas49@gmx.net
}

...Hacia una aldea responsable con la naturaleza y hacia una ciudad responsable con el campo...

Jaime Izquierdo VALLINA (2019)

En el último libro de Jaime Izquierdo Vallina, titulado La ciudad agropolitana. La aldea cosmopolita, el autor señala la ruptura de la relación simbiótica que existió entre la ciudad y el campo hasta la Revolución Industrial. Consistía en un circuito de ida y vuelta en el que se intercambiaban alimentos y productos agropecuarios por manufacturas. Durante miles de años, en la aldea se creó una cultura propia con la que se alimentó a la humanidad y se conservó la naturaleza. El equilibrio se 
rompió cuando se trasladó, desde las ciudades a las aldeas la visión productivista industrial y el falso conservacionismo de la naturaleza. Es preciso que se produzca el reencuentro de ambos espacios para sumar las sinergias necesarias con las que afrontar la grave crisis ambiental global y el reintegro de los humanos en la biosfera, como un componente más.

Inspirados en la esencia de ese mensaje nos propusimos preparar éste dossier, titulado: Paisajes culturales construidos para cultivar y habitar: retos hacia su sostenibilidad. Surgió la idea de aglutinar trabajos sobre paisajes culturales propios de medios rurales con otros de igual signo, pero situados en espacios urbanos. El objetivo general del presente dossier consistió en presentar trabajos o estudios que, desde diferentes disciplinas ofrezcan miradas convergentes hacia los paisajes culturales y su patrimonio. Se propone pues una mirada conjunta en la que se integren éstos como incubadoras de cultura, con valores socioeconómicos y patrimoniales, y con aptitudes para afrontar los retos de desarrollo sostenible del futuro.

\section{PAISAJE CULTURAL Y PATRIMONIO}

El concepto de paisaje cultural tiene casi un siglo de edad. Carl Sauer, geógrafo de la universidad de Berkeley (California) lo acuña en su artículo «La morfología del Paisaje» (1925). Diseña un método de análisis de esos paisajes entendiendo que son creados a partir de formas superpuestas al paisaje natural. Es uno de los fundadores de la escuela de Geografía Cultural. Desde sus primeros estudios mostró su preocupación por la destrucción de la diversidad cultural y por la salud ambiental del planeta.

Con el paso del tiempo y desde instituciones dedicadas a la conservación del patrimonio y del paisaje (UNESCO y Consejo Europeo) se retoma y redefine dicho concepto, en la Convención del Patrimonio Mundial (UICN, 1992) y en el Convenio Europeo del Paisaje (2000), respectivamente. Los reconocen como bienes culturales o partes del territorio que representan o se perciben como obras conjuntas del hombre con la naturaleza o de la interacción de factores naturales y humanos. Ésta fusión conceptual nos permite comprobar que, en esencia, se refieren a los paisajes culturales como resultantes de la relación sociedad-naturaleza. De ella surge una cultura como legado a conservar (visión patrimonial) y un paisaje o espacio geográfico que se puede percibir, disfrutar y gestionar (visión paisajística).

La definición más holística e integradora de paisaje cultural es la que aporta el Plan Nacional de Paisaje Cultural (2012), que dice así: «Paisaje cultural es el resultado de la interacción en el tiempo de las personas y el medio natural, cuya expresión es un territorio percibido y valorado por sus cualidades culturales, producto de un proceso y soporte de la identidad de una comunidad» (CARRIón GúTIEZ, 2015:25)

En ella se incluyen las dimensiones que componen los paisajes culturales: el espacio, el tiempo y la percepción (de los visitantes y de los habitantes). Es un concepto complejo y polisémico, por lo que para la salvaguarda (documentación/ investigación, formación/ difusión y gestión) de los paisajes culturales, se requiere de trabajo en equipo multidisciplinar.

La tipología de paisajes culturales propuesta por UNESCO tiene en cuenta 
su realidad compleja, integrada por componentes naturales y culturales, tangibles e intangibles. Consta de 3 tipos principales: los paisajes claramente definidos y creados intencionadamente (parques y paisajes ajardinados), los paisajes evolucionados orgánicamente, fósiles o activos (resultado del desarrollo de una actividad económica o imperativo social, administrativo y/o religioso) y los paisajes culturales asociativos. Y, en el Plan Nacional de Paisaje Cultural (PNPC), se identifican 9 categorías de paisajes culturales. Éstas se han definido atendiendo a la actividad de mayor capacidad configuradora de paisajes culturales, desde una perspectiva histórica y son: los vinculados a las actividades del sector primario (agrícolas, ganaderas, forestales, pesqueras), artesanales, industriales, grandes infraestructuras (de comunicación y transporte e hidráulicas), actividades de intercambio y comerciales, sistemas urbanos y asentamientos históricos, actividades ofensivas-defensivas, escenarios de acontecimiento históricos, actividades relacionadas con acontecimientos sociales de carácter lúdico, simbólicos, religioso, artístico, e itinerarios y rutas generadoras de paisajes culturales (CAmbón Freire, 2009; Carrión Gútiez, 2015; Miguel Rodríguez, 2015).

Conviene señalar que el propio concepto de paisaje cultural ha evolucionado, ganando en complejidad, con nuevas visiones/valoraciones (del valor universal al valor social) y, además para su conservación y gestión se apuesta por la concurrencia de profesionales de diferentes disciplinas y ramas del conocimiento (ciencias sociales, humanas, ambientales y tecnológicas).

Los tipos de relaciones hombre-medio son muy diversas, según la «intencionalidad» y la «disponibilidad de recursos». El espectro de modelos de relación varían entre dos polos extremos de aprovechamiento, la simbiosis y la destrucción de la naturaleza. De la interacción continuada en el tiempo entre sociedad y medio, no sólo resultan paisajes sino también paisanajes, grupos humanos con su idiosincrasia y su manera de relacionarse con el medio y todo un bagaje de sabiduría y de señas de identidad. Según señala Unamuno, de la correspondencia entre paisaje y paisanaje surge la esencia e identidad de una región o un país, siendo el paisanaje «la reunión íntima entre el paisaje y la humanidad que vive en él y que: «le llena y da sentido y sentimientos humanos...» (UNAMUNO, 2006: 78).

Pero, además, los paisajes culturales fósiles y activos se caracterizan por estructurarse mediante un conjunto de bienes muebles, inmuebles y manifestaciones inmateriales. En ese sentido todo paisaje cultural conlleva patrimonio o herencia cultural de una comunidad que puede presentar mayor o menor valor histórico, artístico, arquitectónico, arqueológico, etnográfico, bibliográfico, documental, lingüístico, paisajístico, industrial, científico, técnico o de cualquier otra naturaleza.

El patrimonio cultural es el testimonio de un tipo de relación viva o relicta con el medio y en cualquier caso tiene valor para la diversidad y el potencial cultural de una comunidad, para la generación de identidades colectivas, la cohesión social y territorial y la producción económica. En este sentido hay que entender que el patrimonio es un vehículo importante para la transmisión de experiencias, aptitudes y conocimientos entre las generaciones, que enriquece el capital social conformando un sentido de pertenencia o que es fuente de inspiración para la creatividad y la innovación, entre otros muchos aspectos.

Por otro lado, el patrimonio cultural es, además de un producto, un proceso. El reconocimiento social y, por ende, institucional, de su valor es intrínseco a su 
naturaleza patrimonial. Esto conlleva que el relato y la conciencia social del valor patrimonial sea un hecho fundamental y que, por tanto, el reconocimiento no sea un activo objetivo e inalterable, sino que tenga una dimensión intersubjetiva que cambia en la medida en que también lo hacen las sociedades.

El carácter dinámico en la conceptualización del patrimonio cultural se ha materializado, en una visión diacrónica, desde un enfoque monumentalista a otra holística y desde el énfasis del bien aislado, en el que como mucho se reconoce el entorno, al del lugar, el conjunto edificado, el territorio o el paisaje.

Este es el caso, por ejemplo, del paisaje agrario de bancales, en el que además de las técnicas o saberes que dan lugar a este modelo territorial, el propio paisaje en su conjunto se revela como el principal elemento patrimonial, al ser resultado fenosistémico de un modo de usar el territorio por sociedades agrarias pasadas y presentes. $\mathrm{O}$ el caso de barrios y conjuntos históricos, en los que, además de la posible existencia de bienes inmuebles con especial valor, la dimensión patrimonial viene dada por el paisaje urbano en sí, como expresión de un modo de organización pasado o de hechos históricos de gran relevancia para el imaginario social.

\section{PAISAJES CULTURALES AGRÍCOLAS}

A partir de la propuesta de análisis de los paisajes culturales realizada para este dossier han resultado doce artículos que abordan la temática desde dos perspectivas espaciales y desde múltiples miradas (multidisciplinariedad): los relacionados con la actividad agrícola en entornos rurales y los relacionados con actividades industriales, comerciales y residenciales, en espacios urbanos.

De los ocho trabajos que componen el primer bloque, seis se centran en el análisis de los paisajes agrícolas en bancales. Son paisajes ancestrales, construidos hace alrededor de 6.000 años (en Yemen), tras la revolución neolítica (Sandor et al., 2006). El desarrollo de la agricultura y la explosión demográfica consecuente, obligaron a colonizar las laderas de los valles y montañas para fabricar tierras de cultivo, tras colmatar la ocupación agrícola las fértiles llanuras aluviales. Son el resultado de la intervención humana en las laderas, modificando sus características topográficas e hidrogeomorfológicas. Se construyó un tipo de paisaje agrícola tridimensional que requirió del empleo de mucha energía humana y animal, el esfuerzo colectivo de las poblaciones locales y de sofisticados saberes sintonizados con los fenómenos de la naturaleza. Algunos de estos paisajes conforman conjuntos monumentales. Son paisajes con historia, con ingeniosa sabiduría, con tradiciones, expuestos a muchas amenazas (abandono agrícola, erosión, incendios, urbanización, olvido, etc...) en los que se concentran altas tasas de agrobiodiversidad. En esencia, son espacios multifuncionales (AsINSVelis, 2007; Hernández HernándeZ, 2009; LASANTA et al., 2013; Romero et al., 2016; Marco Molina et al., 2018; Romero-DíAz, de Vente y Díaz-Pereira, 2019) y que deben ser considerados, no sólo por sus valores patrimoniales, o por su calidad visual sino como agrosistemas sostenibles y resilientes ante las amenazas del cambio climático.

Con la reciente inclusión de los Conocimientos y técnicas del arte de construir muros en piedra seca en la Lista Representativa del Patrimonio Cultural Inmaterial de la Humanidad (UNESCO, 2018) se ha reconocido y dignificado ese 
antiguo oficio y manual de sabiduría ancestral a tantos hombres y mujeres que han contribuido en la construcción y en el mantenimiento de esas estructuras.

En la Lista de Lugares Patrimonio de la Humanidad de la UNESCO existen unos 25 paisajes culturales con presencia de bancales, distribuidos por todos los continentes. Destacan las inclusiones más recientes, de julio de 2019, del Paisaje de Colinas de vides del "prosecco» de Conegliano y Valdobbiadene (Italia) en donde las vides se cultivan en estrechas terrazas con césped llamadas «ciglioni»; y el Paisaje Cultural del Risco Caído y Montañas Sagradas de Gran Canaria (Canarias, España) en donde existen bellos conjuntos de casas-cueva y bancales de reducidas dimensiones denominados «bocaos»

Las potencialidades de éstos paisajes para afrontar situaciones de crisis sanitaria, ambiental y económica, como la actual pandemia del COVID han sido reconocidas. Por ejemplo, en el Perú la nueva Ley n 31077, de 24 de Noviembre de 2020, declara de interés nacional la rehabilitación y conservación de los andenes por su utilidad e importancia en la producción agrícola. Esto coincide con la agudización de la pobreza y hambruna de miles de peruanos que han regresado a sus chacras en andenes huyendo de la falta de trabajo en Lima.

Conviene añadir a la serie de reconocimientos que reciben los espacios agrícolas en bancales, la Lista de Sistemas Importantes del Patrimonio Agrícola Mundial (SIPAM), elaborada por la FAO. En ella se encuentran 17 sitios con bancales, de los cuales 15 se localizan en Asia, asociados a la cultura del arroz y del té principalmente. Con el apoyo que brinda la FAO a los pequeños agricultores se puede evitar el éxodo rural, conservando las comunidades rurales y sus conocimientos, protegiendo los paisajes frágiles y la agrobiodiversidad.

Por su parte, con la declaración del Decenio de las Naciones Unidas de la Agricultura Familiar (2019-2028) se persigue valorizar ese tipo de agricultura que suministra más del 70\% de los alimentos a escala global. La agricultura familiar ofrece una oportunidad única para alcanzar algunos de los más perentorios Objetivos de Desarrollo Sostenible (ODS), como la erradicación del hambre, la pobreza y la protección del medio ambiente. Al mismo tiempo, se conserva el legado cultural de gestión sostenible de los recursos (agua, suelo, semillas, bosques, etc.) tan necesario para conseguir un Planeta sostenible.

A otra escala y, desde la óptica de la investigación y del activismo en materia de conservación, gestión y difusión de la cultura del bancalismo mundial cabe señalar el importante papel dinamizador de la Alianza Internacional de Paisajes de Terrazas (ITLA). Se trata de una asociación no gubernamental internacional que, desde su fundación en 2010, se dedica a promover eventos (cursos, seminarios, workshops, eventos festivos y lúdicos) en torno a los paisajes de bancales. Destacan las cuatro ediciones de congresos mundiales de terrazas. El último se celebró en Canarias (Gran Canaria y La Gomera), Madeira y Azores, en marzo de 2019, bajo el lema de Re-Encantar bancales (Peters y Junchao, 2011; Bueno de Mezquita y Tillmann, 2015; Alberti, Dal Pozzo, Murtas, Salas, y Tillmann, 2018; Palerm Salazar, 2019)

Esta parte del dossier compila seis artículos que demuestran enfoques actuales con múltiples y diversas capas de percepción y lectura de significados del paisaje cultural agrícola en bancales.

La antropóloga A. Acovitsioti- HAMEAu en su artículo L'aménagement ordinaire d'un versant de colline dans le Var (Provence, France): du lieu vécu au paradigme patrimonial nos presenta la comuna de Saint Anastesie que se ubica en la cumbre de 
la meseta de las colinas de Var Provenza en Francia, exactamente en las pendientes de Perremenguier, cuyo nombre contiene la raíz piedra. El área es conocida como «las piedras que alimentan» ya que sus terrazas son representativas de una zona escarpada de la Provenza y constituye un territorio no institucionalizado (fuera de catalogación patrimonial) pero emblemático. Estaba gobernado por costumbres, hábitos colectivamente establecidos y aceptados que tuvieron vigencia hasta 1950.

Las evidencias de las construcciones de terrazas de piedra seca en las colinas de Perremenguier, así como el diseño del espacio habitable y la presencia de los medios de subsistencia testimonian estilos de vida rural, terrazas en uso, con un arraigado sentimiento de identidad. Estas tierras han sido adquiridas recientemente por la municipalidad con la intención de ponerlas en uso como patrimonio rural, lo cual goza de aprecio.

La autora nos lleva por los procesos de cómo la municipalidad está sentando las bases de esta proyección. Para los pobladores, la aptitud del paisaje en la expresión «las piedras que alimentan» evoca un giro hacia la persistencia de la memoria de los usos y de las estructuras de piedra seca construidas para nutrir la regeneración del lugar. Una opción que les permitiría recrear la esencia del paisaje son las prácticas agroecológicas, labrar las terrazas y alimentarse de sus productos. Sin embargo, los planes de gestión patrimonial de la colina de Perremenguier que proponen las autoridades locales priorizarán los aspectos ambientales y recreativos.

Los autores A. Padilla Blanco, J. A. Marco Molina, P. Giménez Font y Á. SÁNCHEZ PARDO examinan el caso de La construcción 'exprés' de un paisaje aterrazado habitable en un medio inhóspito (Sierra de Salinas, Alicante). El trabajo presenta un panorama general del proceso de colonización en la Sierra de las Salinas en Alicante, España, apoyado en la revisión de documentos de trabajos previos, con lo cual se reconstruye la historia social y las modificaciones de la morfología del paisaje agrario. Para ello los autores consultaron memorias, planos sobre la propiedad de la tierra, sus usos, la cartográfica, archivos audiovisuales y entrevistas.

Nos presentan la Colonia Agrícola de la Sierra de Salinas como una de las que se crearon en España a principios del siglo xx, con la «Ley de colonización y repoblación interior» de 1907. El éxodo rural hacia las grandes ciudades españolas y al extranjero, noventa años atrás era tan alarmante que el Ministerio de Fomento intentó ponerle freno ensayando la aplicación de creación de oportunidades de vida en el campo. Cada unidad familiar tendría la oportunidad de salir de la pobreza al habitar y producir en espacios abandonados, baldíos, y terrenos forestales que requerían mucho trabajo para ponerlos a producir. El ensayo constituía una visión desde el catolicismo social. Las condiciones para la creación de las colonias fueron la cooperación mutua, el apoyo económico y técnico del estado y las formas cooperativistas.

A los 25 años de este ensayo la mayoría de las colonias habían fracasado porque los espacios repartidos a los colonos eran de vocación forestal y no agrícola. El fracaso sucedió a pesar de que pusieron en marcha estudios cuantitativos, agronómicos para determinar la viabilidad del ensayo, que combinaban estudios detallados del clima, las propiedades de los suelos, análisis topográficos, de la escorrentía superficial y procesos de infiltración. También se creó una tipología de tierras de acuerdo al criterio de productividad delimitando tres lotes para la actividad agrícola y uno para la actividad forestal. Sobre esta base de conocimiento 
técnico se reparten los lotes a familias campesinas, analfabetos en su mayoría, totalmente pobres, jornaleros agrícolas, fuerza laboral no cualificada según los documentos de la época.

En el caso de la Colonia Agrícola de la Sierra de Salinas los agricultores constataron que la planificación técnica de cultivos rentables era imposible de cumplir. Con relativa rapidez se dedicaron a cultivar trigo, centeno, avena, guija, cáñamo, judías, patatas, tomates y otras hortalizas para alimentarse hasta que los olivos y la vid comenzaron a rendir. De esta manera desarrollaron su propio conocimiento del trabajo de la tierra, del cuidado del ganado y la cacería mientras que las mujeres se especializaron en las tareas domésticas, la tradición oral, bailar y cantar, celebrar las fiestas propias de la cultura rural.

La gran lección de este caso es que el paisaje aterrazado emerge como una tímida, pero creativa respuesta local a las adversidades del ensayo colonial predeterminado desde los intereses políticos, técnicos y económicos del estado respaldado por el modelo social católico. La gente considerada jornaleros agrícolas absolutamente pobres logra imaginar y crear una comunidad que los descendientes llaman «el espíritu de la colonial». Esta sigue viva gracias a las transformaciones de un paisaje a la medida de sus valores y capacidades.

Muestra de ello es la construcción de muretes de piedra seca entre los bancales y en las eras. No está de más decir que UNESCO, en 2018 reconoció a los constructores de piedra seca del Europa, lo cual ha estimulado la autoestima cultural de los pobladores de esos espacios.

Los paisajes de terrazas también se pueden entender como un sistema territorial con tres diferentes componentes complejos: abióticos, o físicos, o sea el sustrato inerte, sólido, líquido, gaseoso, el relieve, el clima, los ríos, entre otros; bióticos, o biológicos naturales como los animales, la vegetación, la distribución de especies y las formas de asociación. Y el tercer componente es el antrópico, es decir, todo lo relacionado con las actividades humanas. Esos tres componentes del sistema territorial interactúan en diferentes rangos bajo la influencia de los procesos naturales y de la actividad modificadora de la sociedad humana en permanente interacción y desarrollo. (Rigol, 2004)

El siguiente artículo, de J. Mongil Manso, J. Navarro Hevia y J. C. Sanz Belloso titulado Clasificación y caracterización de los bancales de la provincia de Ávila se ubica en un plano que prioriza el estudio de componentes físicos y biológicos. Es una aproximación preliminar de los bancales de la provincia de Ávila, España en el marco de un proyecto que tiene como objetivo la conservación de los bancales como un patrimonio rural tradicional.

Es un planteamiento de desarrollo en su fase inicial cuyo objetivo es detener la degradación del paisaje proyectando las terrazas como agrosistemas. Es decir, planificar la combinación de factores naturales, económicos y sociales con la función principal de proveer alimentos. Los primeros avances del artículo, presentan dos resultados iniciales: distribución de la superficie de bancales en los 15 municipios de la comarca del Valle del Tiétar y la tipología de terrazas caracterizadas en seis categorías basada en criterios técnicos. El punto de vista de los constructores o usuarios de las terrazas está ausente, pues la metodología empleada para el reconocimiento de la zona de bancales han sido orto fotografías aéreas, imágenes de satélite y transectos.

El artículo de F. ZotTele y Á. GonzÁlez SANTANA con el título Faraway So Close. The landscapital proof of concept applied to the terraced landscapes of the Canary Islands 
and the Alps desarrolla una aproximación del vínculo entre lo productivo y lo estético. Según ANGELINI (2018), el paisaje de terrazas desde la percepción sensorial y subjetiva, contiene valores estéticos. Contemplar un espacio segmentado por muros de piedra seca, o laderas inundadas sostenidas por la filigrana de barreras vivas, evoca disfrutar de la belleza como ocurre con una pintura, un dibujo, una escultura, una fotografía. El paisaje de terrazas cobra mayor significado cuando el reconocimiento de lo bello comulga con la acción humana del cultivo de alimentos que nutren la mutua reciprocidad entre la naturaleza y la cultura. Entendemos que lo esencial de las terrazas es el diálogo entre lo estético y lo ético, es decir las terrazas son bellas y generosas.

En este artículo los autores exponen un nuevo método para identificar variables formales y plásticas en base al concepto «capital del paisaje» (del inglés landscapital) que juegan un importante rol en la percepción de la calidad del vino, producto de la viticultura en terrazas en Vallehermoso (La Gomera, Islas Canarias) y el Valle del Cembra, Trentino en los Alpes italianos. El término «capital del paisaje» plantea una conciencia cultural que vigoriza la dimensión productiva de la tierra en vínculo con el arte. Es un tema que se viene investigando desde 2000 a raíz de la Convención Europea del Paisaje, artículo 6 (Consejo de Europa, 2000). ${ }^{1}$

Esta aproximación a la viticultura y al vino posee una complejidad y sofisticación teórica que toma en cuenta múltiples variables de orden subjetivo, así como físicos, biológicos, económicos, sociales, ambientales, culturales que permiten la valoración del territorio aterrazado tanto por los consumidores como por los productores de vino. Una suerte de engranaje de factores estructurales, así como de la sintonía entre percepciones intrínsecas y extrínsecas del paisaje conducen a una nueva dinámica participativa en relación al territorio. Entendiendo la teoría del capital del paisaje, se podría decir que, en la práctica, los procesos en las dos áreas de estudio proponen una actitud proactiva. Consumir vino de terrazas robustece la relación entre el territorio y sus productores, dando como resultado una experiencia empoderadora. En cada sorbo se estaría degustando la epopeya de los productores y las cualidades estéticas, únicas de las terrazas. A su vez, la proyección de estas vivencias en el tiempo y en diferentes escalas de la sociedad extirparía los procesos de abandono e inclusive desvanecerían la desnaturalización de los paisajes de terrazas en territorios únicamente pintorescos.

Desde la perspectiva que entiende los paisajes de terrazas como producto de la diversidad cultural se pone en relieve el sello común de la amalgama de lo sensorial, lo cognitivo y lo afectivo. Es a través de las diversas miradas de los habitantes locales, que nos acercamos a reconocer lo físico, visible desde ángulos muy distintos. Distinguen una red de otros elementos ocultos no evidentes como la velocidad y la voluntad del agua, clasifican el agua por ciclo de edades, ven en la intensidad del fulgor de las estrellas las señales para las actividades agrícolas, distinguen los colores y olores del suelo, interpretan la ruptura de las leyes naturales como las causas del cambio climático, reconocen el comportamiento de las plantas y sus interacciones como seres vivos, y como muchos pedreros advierten los mensajes de las piedras. Son formas de entender y vivir el paisaje para producir sintiéndose parte del medio inmediato circundante (GAVAZZI, 2010)

Los dos artículos siguientes reconocen la sabiduría campesina como elemento a favor de la sostenibilidad de las terrazas. F. WAHOno y T. Puspitanati

1 Consejo de Europa, 2000: Convenio Europeo de Paisaje, Florencia [en línea]. Disponible en: https:/ / rm.coe.int/16802f3fbd [Consulta: 02/12/2020]. 
en el artículo titulado Be friendly with nature: a case of terrace farming in the Dieng Plateau, Central Java, Indonesia nos plantean el reto de frenar la erosión de los suelos que afecta a los campesinos que cultivan en las terrazas de la meseta de Dieng en Java Central, Indonesia. Dos comunidades, Sikunang y Wadaslintang Alto, participan en un proceso planteándose la pregunta de si es posible vencer la erosión valiéndose de la sabiduría ancestral transformando las técnicas agrícolas antiguas, más amables con la naturaleza en «nuevas» soluciones sostenibles. El artículo se basa en el trabajo de campo antropológico de carácter participativo realizado en las dos comunidades entre 2001 y 2004.

La meseta de Dieng está ubicada a 2.060 m.s.n.m., y tiene un clima de montaña con gran variabilidad de la temperatura diaria. Originalmente, la meseta fue la caldera del volcán Di Hyang, que significa la «residencia de los dioses», probablemente en alusión a la fertilidad de los suelos. Los procesos naturales y culturales son dos aspectos íntimamente vinculados en las cosmovisiones de los pobladores quienes han sincretizado el animismo, hinduismo, budismo, y desde el siglo XVII el islamismo. Hoy se practica un sincretismo religioso en toda la región que repercute en la relación de los campesinos con sus prácticas agrícolas.

En relación a la interrogante sobre el rol del saber ancestral, los autores contextualizan este reto en una situación contrastante de gran actualidad nacional. Por un lado, el ingreso de productos transgénicos a Indonesia con apoyo del ministerio de agricultura y por otro lado el anuncio de la Universidad Católica comunicando el descubrimiento de un remedio contra la influenza aviar en base a extractos de plantas endémicas. Esto ilustra dos modelos de conocimiento muy diferentes: el científico tecnológico y la sabiduría ancestral. So modelos que poseen valores político-culturales opuestos que se transmiten a la población agrícola, el primero comunica los valores del dominio sobre la naturaleza y el segundo implica el ser parte de la naturaleza.

El desafío para encontrar maneras de detener la erosión del suelo no se trata de la imposición de un modelo sobre el otro ni de opciones absolutas entre los saberes occidentales vs. orientales. Se trata más bien de procesos de reflexión participativos a través de los cuales se presenta una gama de saberes y prácticas agrícolas que los campesinos pueden escoger, como la agricultura orgánica, agricultura natural, LEISA, la agricultura popular, las técnicas minimalistas, permacultura. Estas agriculturas alternativas se practican sobre la base de la unidad familiar, sin detrimento del medio ambiente y posibilita la sostenibilidad de las terrazas como fuente de sobrevivencia y de estilos de vida. Sobe todo integra el respeto por los principios de la naturaleza, es decir la perpetuidad de una relación simbiótica entre los seres humanos y la naturaleza. Sabio criterio para el proceso de innovación de la agricultura de los campesinos que asegura la biodiversidad, el agua, el suelo y sobre todo la continuidad cultural que provee de sentido a la vida en paisajes de terrazas, es decir, seguir siendo los hijos del Volcán.

M.A. Salas y T. Tillmann con el artículo titulado El poder transformador de los saberes en paisajes de terrazas aportan su mirada antropológica de la cultura de las terrazas y se manifiestan defensores de la justicia cognitiva con la que se promueve la diversidad cultural propia de esos paisajes. A través de las voces de los campesinos, técnicos, investigadores y habitantes de espacios abancalados del mundo, y a través de la metodología de Investigación Acción Participativa practicada a lo largo de 10 años de trabajo, desarrollado en el contexto de los 
cuatro congresos mundiales de terrazas, muestran la diversidad de apreciaciones que existen en torno a las tres dimensiones de estos paisajes culturales: espacio, tiempo y saberes. También se reflexiona sobre la necesidad de conservar esos espacios manteniendo la función para las que fueron construidos A la vez se demuestra que son agrosistemas sostenibles por la economía de recursos (gestión de agua, suelo y semillas) y por sus funciones ambientales.

Defienden el valor de la diversidad cultural de saberes de los pobladores y cultivadores de las terrazas en donde se practica la agricultura familiar que concentra el peso de la agrobiodiversidad y se proporciona el alimento al $70 \%$ de la humanidad. Denuncian el grado de amenaza que experimentan los pobladores y las culturas de las terrazas por la agricultura industrial, la globalización, el capitalismo y el cambio climático. Son agrosistemas que salvaguardan la biodiversidad, el medio ambiente y la cultura. Han demostrado haber sido resilientes a cambios climáticos en el pasado y pueden contribuir a mitigar los efectos del cambio climático ante la actual escasez de alimentos, agua y suelos útiles para la agricultura.

Además de los análisis presentados sobre paisajes culturales aterrazados, se incluyen otras dos aportaciones centradas en otras tipologías de paisajes agrarios. $\mathrm{M}^{\mathrm{a}}$ Carmen CAÑIZARES en su artículo titulado Valorización del patrimonio industrial agroalimentario: Los silos del «Proyecto Titanes» (Ciudad Real, España) ha analizado el procedimiento de puesta en valor del ingente patrimonio industrial agrario que conforman los silos y graneros que se extienden por gran parte de la geografía española.

En el contexto de la España rural, los silos y graneros son elementos de gran importancia como muestra de las políticas agrarias que se pusieron en marcha durante el siglo xx y como registro paisajístico de tecnologías y formas de vida pasadas. Enfatizan los sentimientos de identidad de los habitantes de su entorno y pueden tener un valor estético por la calidad de su arquitectura. A pesar de esto, este patrimonio industrial no ha merecido mayor atención y hasta finales del siglo xx no aparecieron iniciativas sociales e institucionales para promover su conservación y puesta en valor. Como resultado, algunos silos y graneros de la Red Nacional se han transformado en espacios culturales, centros de interpretación, edificios administrativos, almacenes municipales o espacios asociativos. No obstante, una buena parte de ellos languidece en desuso y se encuentra en mal estado de conservación.

El caso analizado por la autora se centra en diez silos ubicado en áreas rurales o núcleos urbanos de reducida dimensión en la provincia de Ciudad Real (Castilla-La Mancha, España) cuya valorización se ha basado en la potenciación del rol paisajístico y monumental de estas edificaciones a través del uso del arte urbano, lo que ha supuesto que sus muros exteriores hayan sido cubiertos por murales. Como resultado de esta práctica, los edificios se han incluido en rutas y guías turísticas. Además, el proceso de puesta en valor tiene el importante matiz de estar en el marco de un proyecto cultural inclusivo que ha permitido la participación de población con diversidad funcional, de tal modo que, a través de la actuación artística y el desarrollo de prácticas inclusivas, estos recursos territoriales se han convertido en un factor de desarrollo local endógeno.

La interpretación es posiblemente una de las prácticas de más interés a la hora de plantearse la valorización del paisaje cultural agrario. MorALES MIRANDA (2015) define la interpretación del Patrimonio como un proceso creativo de estrategias que ayuda a conectar intelectual y emocionalmente al visitante con el 
bien patrimonial para que lo aprecie y lo disfrute. Implica cumplir con la función social del patrimonio fomentado identidad y difusión cultural. No obstante, la interpretación a través de la musealización tiene importantes problemas derivados de su frecuente falta de rentabilidad económica, reconstrucción de relatos sin base histórica o tematización del contenido. Por ese motivo, cuando la interpretación patrimonial surge desde la concienciación ciudadana adquiere una dimensión de gran interés.

Todo esto tiene su mejor expresión en la creación del Proyecto Cultural de Desarrollo Comunitario de La Aldea, en Gran Canaria, en el que la interpretación se instrumentaliza mediante una red de 15 museos etnográficos, tal como se analiza en el capítulo elaborado por H. Moreno, A. SAntana y J.M. Parreño titulado Beneficio social de los ecomuseos en el territorio. El Proyecto Cultural de Desarrollo Comunitario de La Aldea como caso de estudio.

En este municipio se ha desarrollado una red de ecomuseos que se compone de diferentes infraestructuras y edificios históricos repartidos por todo el valle de La Aldea en los que se ofrece una visión global de la cultura y el territorio procedente de la memoria colectiva de la población.

El hecho de arrancar de la memoria colectiva como interpretación holística del patrimonio tangible e intangible del municipio sólo es posible con un modelo de gestión alternativo, de base comunitaria, fundamentado en el voluntariado, en la cesión temporal y desinteresada de inmuebles y en el carácter no lucrativo de la actividad. Además, la musealización en vivo, que es el lenguaje museístico predominante en este caso, se relaciona con un alto nivel de implicación social. Con todo ello, la conservación e interpretación del paisaje cultural agrario se organiza desde abajo.

Esto da una enorme eficacia en todas estas tareas, aunque no exentas de dificultades derivadas de la infrafinanciación y la falta de modelos profesionales de gestión. No solo se garantiza la preservación intersubjetiva del patrimonio y de tradiciones y vivencias, sino que se estimulan y transmiten a nuevas generaciones sentimientos identitarios, se favorece la integración social de la población de más edad dado que esta tiene mucho peso en el conjunto del voluntariado, se incrementa la cohesión social a través del desarrollo de fórmulas asociativas y se dinamiza la actividad económica, ya que los visitantes suelen usar servicios de restauración, adquirir productos locales en su visita y, ocasionalmente, se alojan en el municipio.

En definitiva, la interpretación del patrimonio a partir de un modelo de gestión comunitario en este caso convierte al paisaje cultural en algo vivo en la medida en que, por un lado, es sentido como algo valioso por una parte de la población, $y$, por otro, es percibido como un elemento identitario por los visitantes locales. Todo esto no suele ocurrir en los modelos de interpretación de arriba abajo, con escasa implicación social, en los que el patrimonio se percibe como algo del pasado, ajeno a la vida diaria de la población.

\section{PAISAJES CULTURALES URBANOS}

La ciudad alberga también paisajes culturales de gran valor. Se trata de espacios urbanos moldeados a lo largo del tiempo que destacan por la singularidad y características de sus emplazamientos, entramados y edificaciones, 
como expresión de un modo de producción generalmente pretérito (SANTACANA y SERRAT, 2009). Estas características reportan especial valor, sobre todo en el actual contexto de estandarización global. Sin embargo, si hay un espacio sometido a intereses económicos especulativos es la ciudad, motivo por el que la conservación y gestión de los paisajes culturales urbanos o de algunos de sus elementos resulta una tarea compleja, sobre todo si no media una clara institucionalización de su conservación (ZÁRATE MARTín, 2010).

A pesar de ello, en las últimas décadas se han sucedido iniciativas que pretenden favorecer la conservación de los paisajes culturales urbanos. Un hito al respecto es la redacción y aprobación en 1987 de la Carta Internacional para la Conservación de las Ciudades Históricas y Áreas Urbanas Históricas por el Consejo Internacional de Monumentos y Sitios (ICOMOS). ${ }^{2}$ Según esta Carta, los valores a conservar son el carácter histórico de la población o del área urbana y los elementos materiales y espirituales que determinan su imagen, tales como la trama y el parcelario; la relación entre los diversos espacios urbanos, la forma y el aspecto de los edificios, las relaciones entre población o área urbana y su entorno y las diversas funciones adquiridas por la población o el área urbana en el curso de la historia.

El Convenio Europeo del Paisaje (2000, en vigor en España desde 2008) y la Declaración de la UNESCO de Xi an sobre la "Conservación del entorno de las estructuras, sitios y áreas patrimoniales» (2005) supusieron un paso más en la conceptualización paisajística del legado urbano a proteger y han favorecido que las normativas autonómicas del suelo y ordenación del territorio introduzcan el paisaje como criterio de protección en las ciudades (ZOIDO NARANJO, 2002; Parreño Castellano y Díaz Hernández, 2010; Zárate Martín, 2011). El paisaje, su mantenimiento o su recuperación, se ha generalizado como criterio de planificación urbana. Los Principios de La Valeta para la salvaguardia y gestión de las poblaciones y áreas urbanas históricas terminaron por sistematizar los principios generales de gestión y conservación del paisaje cultural urbano. ${ }^{3}$ Como se señala en el preámbulo de este documento se presta una mayor consideración al patrimonio histórico en el contexto territorial; a sus valores inmateriales, a los usos tradicionales; al papel del espacio público como lugar de interacción social y otros factores como la integración social o los ambientales.

Es frecuente que los bienes inmuebles en los paisajes urbanos tengan cambios en su funcionalidad a lo largo del tiempo. Este cambio de uso es el que propicia en muchos casos la conservación patrimonial. El uso turístico y el residencial son la expresión más generalizada al respecto, aunque caben otros usos como el cultural o el comercial. Es indudable que la reutilización de elementos patrimoniales permite su conservación en la mayor parte de los casos (ZÁRATE MARTín, 2017), pero no está exenta de riesgos derivados de los propios proyectos de recuperación y adaptación funcional en algunos casos, y de la conservación segregada de todo significado cultural más allá del propiamente monumental, por otro.

En la apropiación turística de los bienes patrimoniales en cascos históricos

2 ICOMOS, 1987: Carta Internacional para la Conservación de las Ciudades Históricas y Áreas Urbanas Históricas (Carta de Washington) [en línea]. Disponible en: https://icomos.es/wp-content/ uploads/2020/01/towns_sp-1.pdf [Consulta: 02/12/2020].

3 ICOMOS, 2011: Principios de La Valeta para la salvaguardia y gestión de las poblaciones y áreas urbanas históricas [en línea]. Disponible en: https://icomos.es/wp-content/uploads/2020/01/25. Principios-de-La-Valeta-2011.pdf [Consulta: 02/12/2020]. 
este riesgo de devaluación patrimonial es especialmente relevante. La superación de la capacidad de carga turística lleva en muchos casos a los cascos históricos a una hiperespecialización que termina por convertir al paisaje urbano en un mero escenario banalizado. Este hecho hace especialmente valiosas las prácticas de apropiación turística que manifiestan una clara compatibilidad de usos, como la analizada por M. RodríGuez, M.R. GonzÁlez y J. Domínguez en su aportación titulada Patrimonio urbano y alojamientos turísticos en Cienfuegos (Cuba). En este estudio, centrado en una ciudad declarada Patrimonio Cultural de la Humanidad y en el particular contexto socieconómico de Cuba, se muestra como el uso turístico, a través de la oferta de alojamiento hotelero y la de las casas privadas de uso turístico, repercute de manera positiva en la valorización patrimonial del paisaje cultural.

En el análisis se muestra cómo la apropiación está favoreciendo, en primer lugar, la recuperación de edificios y espacios públicos. En segundo lugar, se explica cómo las familias que ofrecen el servicio de casa particular complementan sus rentas lo que conlleva que la población se mantenga en la zona, se genere estabilidad social y se mejore el paisaje urbano. Y, por último, la apuesta por un modelo alojativo disperso en el que el residente acoge al turista implica una relación residente-cliente reforzada, lo que, desde el punto de vista patrimonial, supone que la preservación de los elementos patrimoniales sea más integral, incluyendo otros aspectos menos tangibles. La patrimonialización del paisaje cultural se convierte en una construcción social (NoGUÉ, 2007).

Indudablemente el modelo de negocio, de fuerte impronta comunitaria, da otro significado al patrimonio, pero no es el único factor. La dimensión de la oferta alojativa y la capacidad de carga territorial subyacente es un elemento crucial que aleja al paisaje de la estandarización y de la pérdida de significados.

Si bien en Cienfuegos el desarrollo de actividades turísticas se puede valorar como un mecanismo de conservación patrimonial ligado al mantenimiento de la población y del uso residencial, en el caso de Ciudad Jardín, en Las Palmas de Gran Canaria, se da la situación contraria. Este barrio, como se analiza en el artículo de G. Morales, S. Hernández y Y. LozAno titulado La ciudad jardín de Las Palmas de Gran canaria como paisaje cultural urbano, basa su valor como patrimonio cultural en su proceso histórico de conformación a través de la generación de un paisaje urbano de baja densidad y gran calidad arquitectónica entre finales del siglo XIX y la década de los cincuenta del siglo pasado. Esto ha motivado que un número elevado de inmuebles y elementos urbanos estén protegidos, lo que ha permitido la conservación de buena parte del patrimonio cultural.

Sin embargo, la protección de bienes aislados no ha sido una herramienta eficaz para la conservación del paisaje cultural en un sentido global y en el barrio existen dinámicas, ya sostenidas en el tiempo, por la que muchos inmuebles han perdido la función residencial en favor de la creación de equipamientos sanitarios, educativos y deportivos de carácter privado y de servicios administrativos públicos. La pérdida del valor cultural tiene su mejor expresión en el hecho de que el barrio se haya convertido en un gran aparcamiento al aire libre.

La falta de una protección más integral, como la que proporciona la declaración de Bien de Interés Cultural con la categoría de conjunto histórico, ha propiciado que la conservación patrimonial haya sido sólo parcial. Lo que fue un paisaje cultural urbano de fuerte impronta, se ha quedado en un catálogo de bienes culturales de carácter arquitectónico o monumental. El paisaje cultural se 
ha transformado en un escenario monumental producto de la concurrencia de numerosas inversiones en un mercado especulativo sin cortapisas, al que ahora se suma la vivienda turística. Como señalan los autores, parece que el mantenimiento de la población y de la cohesión social se revelan como factores claros para la conservación de un paisaje cultural urbano con significado. El caso contrario lo lleva a la transformación en otra realidad diferente.

La construcción social del paisaje urbano depende del modo de producción y de factores naturales, políticos, religiosos y sociales. En este último sentido, el paisaje urbano expresa las diferencias sociales y los procesos de segregación residencial pero también los valores y las identidades colectivas. En este sentido, la memoria histórica es una de esas dimensiones que favorece la continua reflexión sobre el alcance del patrimonio. La memoria histórica, como reclamación social que reivindica una relectura de hechos históricos conflictivos y sin resolver y que centra su discurso en la reparación y dignificación de los damnificados, tiene que ver con la historia, pero también con los recuerdos, los sentimientos y las percepciones. Todo ello la acerca al mundo del patrimonio, tal como este se entiende hoy, como un proceso de asignación de valores por parte de la sociedad.

La memoria histórica se materializa a través de lugares y escenarios propios del paisaje cultural. Como señalan V. SALINAS y R. Silva en su artículo denominado Memoria histórica y patrimonio. Consideraciones conceptuales y metodológicas aplicadas al caso de Sevilla, el reconocimiento patrimonial de estos lugares y escenarios ha seguido caminos complejos y no se puede hablar de una teoría homogénea y monolítica a escala mundial. No obstante, la asignación de valores patrimoniales puede abordarse desde la conceptualización de sitio histórico y de espíritu de lugar, ambas basadas en cartas aprobadas por ICOMOS en 1982 y 2008, respectivamente. ${ }^{4}$

Un sitio histórico es un paisaje específico asociado a un hecho memorable como, por ejemplo, un suceso histórico importante. El espíritu del lugar, por su lado, viene dado por el conjunto de los elementos materiales (sitios, paisajes, construcciones, objetos) e inmateriales (memorias, relatos, ritos, festivales, conocimientos), físicos y espirituales que dan sentido, valor, emoción y misterio al lugar. Ambos conceptos, según estos autores, permiten el encaje de la memoria histórica a una escala global, pero además señalan que, en el caso de Andalucía, la valorización patrimonial se puede realizar también a partir de la Ley de Memoria Democrática, ya que este texto normativo prevé la creación de un Inventario de Lugares de Memoria Democrática compuesto por espacios, inmuebles o parajes con interés histórico por haberse desarrollado en ellos hechos de clara significación histórica, simbólica o que han tenido una clara repercusión en la memoria colectiva vinculados con la lucha del pueblo andaluz por sus derechos y libertades democráticas.

Indistintamente de la vía institucional que se considere más apropiada para la valorización patrimonial de la memoria histórica, la relación entre ésta y el patrimonio dista de ser madura, a pesar de que en los últimos años se ha avanzado

4 ICOMOS, 2008: Carta ICOMOS para Interpretación y Presentación de Sitios de Patrimonio Cultural [en línea]. Disponible en: https://icomos.es/wp-content/uploads/2020/01/14.2.Carta-ICOMOSpara-Interpretaci \%C3\%B3n-y-Presentaci\%C3\%B3n-de-Sitios-de-Patrimonio-Cultural.pdf [Consulta: 02/12/ 2020]; ICOMOS, 2008: Declaración de Quebec sobre la Preservación del Espíritu del Lugar [en línea]. Disponible en: https://icomos.es/wp-content/uploads/2020/01/13.DECLARACI\%C3\%93NDE-QUEBEC.pdf [Consulta: 02/12/2020]. 
en este propósito

Más allá de la identificación y protección patrimonial, el legado cultural e histórico se enfrenta a grandes retos para su recuperación, conservación, acrecentamiento, difusión, valorización y transmisión a generaciones futuras, de forma que sea una herramienta real para la cohesión social, el desarrollo sostenible y la identidad cultural y territorial.

Un último aspecto de gran interés es como la ciudad en su proceso de crecimiento puede usar y valorizar elementos paisajísticos urbanos o situados fuera de la ciudad en el pasado que están relacionados con modos de producción pretéritos. Aquí tenemos el debate de cómo la ciudad global destruye o integra elementos patrimoniales de la ciudad industrial o preindustrial. En otros términos, qué hace con el legado de paisajes culturales que ya han desaparecido generalmente y del que sólo se conservan elementos singulares.

El reconocimiento y valorización del patrimonio industrial es el caso analizado en el estudio de J. MANZANo y F. MiRELES, en relación con los hornos de cal existentes en las islas de Fuerteventura, La Gomera, Gran Canaria y Tenerife, en Canarias. Desde el siglo XVI y hasta entrado el siglo xx, la construcción en Canarias favoreció la producción de cal a partir de la quema de carbonatos cálcicos. Como consecuencia, los hornos de cal se multiplicaron en todas las islas $\mathrm{y}$, especialmente, con el crecimiento de las ciudades y la actividad portuaria desde las últimas décadas del siglo XIX, se erigieron en ellas hornos reverberos que permitían una mayor producción

Como exponen los autores en su artículo titulado Situación de los hornos de cal a través del tiempo en las ciudades de Canarias, estos hornos de gran tamaño que se situaban en el entorno de los principales puertos, junto a depósitos de caliche y en la periferia o en el interior de las ciudades, fueron entrando en desuso en la medida en que la cal fue sustituida por el cemento, lo que conllevó su desaparición en muchos casos.

En el entorno de núcleos urbanos en los que el crecimiento urbano fue más tardío, como Puerto de la Cruz en Tenerife, San Sebastián en La Gomera o Puerto del Rosario en Fuerteventura, estas estructuras urbanas industriales tuvieron mejor suerte. La declaración como Bienes de Interés Cultural ha facilitado su permanencia y la puesta en marcha de iniciativas de conservación.

En este sentido, la puesta en valor muestra un panorama muy diverso. La monumentalización patrimonial en el espacio público de la ciudad ha sido la vía más frecuente. Pero la función social ha encontrado otros caminos como la creación de espacios abiertos socio-recreativos de fuerte impronta cultural o la musealización para interpretación patrimonial.

Aunque en todos estos casos, las estructuras industriales han encontrado un sitio en la trama urbana, favoreciendo la creación de paisajes urbanos con identidad opuestos a los procesos de «urbanalización» (MuÑOz, 2008), en algunos los hornos de cal parecen ser sólo respetados por el crecimiento urbano, mientras en otros ordenan su propio entorno, siendo el patrimonio industrial el elemento que estructura el paisaje urbano actual. 


\section{CONCLUSIONES}

Hemos visto como la sucesión de diferentes modos de apropiación del medio natural y organización social y política ha determinado la aparición de diferentes paisajes culturales. En este sentido, el paisaje cultural se define por las características naturales, la estructuración socio-política, la organización territorial y la dinámica temporal en un proceso de construcción social continuo. Los paisajes pueden seguir activos o tener una naturaleza relicta. En el primer caso, los bienes materiales e inmateriales que lo componen tienen valor como recurso o activo territorial para el propio sistema de explotación. En el segundo, estos bienes se han transformado en un legado o patrimonio que puede ser usado o no como recurso de los sistemas posteriores, lo que depende de la concomitancia dialéctica de diferentes intereses y de la percepción social del paisaje. La sostenibilidad integral de los paisajes o de sus elementos patrimoniales de manera aislada es, por tanto, un tema de la máxima importancia y, como consecuencia, se han ido aprobando acuerdos y convenios internacionales y normativas nacionales que han incluido al paisaje y su valorización patrimonial como un elemento clave en la ordenación del territorio.

La sostenibilidad de los paisajes culturales implica conocer el paisaje, descubriéndolo con los ojos, desde la mirada de sus habitantes, reconocer las transformaciones de maneras integrales y con visiones de creación y recreación, atendiendo a los mensajes de la lógica de la naturaleza. Así lo hemos podido reseñar en el caso de los paisajes aterrazados aún activos de Provenza, los Alpes, Italia, las Islas Canarias, Java y otros muchos lugares, en los que hay un enfrentamiento entre la conservación y la transformación del uso y la búsqueda de nuevas fórmulas de comercialización que permitan el mantenimiento de la actividad. En todos estos casos, la sostenibilidad se basa en la toma conjunta de decisiones de todos los actores sociales y políticos vinculados con el futuro de las terrazas, teniendo en cuenta los valores y la conciencia de los grupos culturales locales y las múltiples maneras de integración y simbiosis con la naturaleza que están en las prácticas y saberes locales.

La conservación de los elementos patrimoniales de paisajes culturales relictos no es un asunto fácil en las dinámicas globalizadoras actuales, a pesar de las múltiples ventajas económicas, sociales e identitarias que acarrea. La persistencia de todos estos elementos materiales e inmateriales tiene que conllevar el registro y el estudio de los mismos y el desarrollo de normativas apropiadas para la salvaguarda y de medidas concretas de protección. Así lo vimos en recursos patrimoniales tan diversos como los bancales del valle del Tiétar, la memoria histórica y democrática de los andaluces o barrios históricos como Ciudad Jardín en Las Palmas de Gran Canaria.

En otros casos, la sostenibilidad se puede instrumentar a través de la educación y sensibilización de la comunidad, como en el caso de los ecomuseos de La Aldea en Gran Canaria, o del desarrollo futuro de museos institucionalizados como en los bancales de Alicante o en los hornos de cal de Canarias. Por último, la conservación sólo parece posible en ocasiones a través de la monumentalización y generación de atractivos culturales o la reasignación sostenible de usos. Entre los abundantes ejemplos de lo primero cabe citar el que se está desarrollando con los silos de Ciudad Real. La transformación de usos sostenible encuentra su mejor ejemplo en este monográfico en el estudio realizado para el patrimonio 
arquitectónico de Cienfuegos en Cuba, en el que la actividad turística se convierte en una alternativa posible.

De todas las realidades presentadas se puede deducir la importancia de la implicación social de las comunidades locales como factor de sostenibilidad, la necesidad de definir nuevos usos compatibles con la conservación, la relación entre sostenibilidad y conciencia social y el desarrollo de modelos de gobernanza participativos. Sin todos estos factores es imposible que se lleve a cabo una transición en el mundo que permita el mantenimiento de la diversidad de sus paisajes agrarios y urbanos.

\section{REFERENCIAS}

Alberti, F.; Dal Pozzo, A.; Murtas, D.; Salas, M.A.; Tillmann, T., eds. (2018): Paesaggi terrazzati: Scelta per il futuro. Terzo Incontro Mondiale, Regione del Veneto.

Angelini, M. (2018): «La política della bellezza de lo spazio rurale», en F. Alberti, A. Dal Pozzo, D. Murtas, M.A. Salas y T. Tillmann, eds., Paesaggi terrazzati: scelte per il futuro. Terzo Incontro Mondiale, Regione del Veneto, Venezia: 161165.

Asins-Velis, S. (2007): «Los aterrazamientos mediterráneos. Paradigma ambientalagro-cultural», Cuadernos de sostenibilidad y patrimonio natural, El paisaje mediterráneo: opciones de multifuncionalidad, 11:81-91.

Bueno de Mezquita, M.; Tillmann, T., eds. (2015): il Congreso Internacional de Terrazas. Encuentro de culturas y saberes de terrazas del mundo, Agencia de Cooperación Internacional del Japón/JICA y Centro de Estudios Regionales Andinos Bartolomé de Las Casas/CBC, Cusco. Perú.

CAmbón Freire, E.C. (2009): «Paisajes culturales como patrimonio: criterios para su identificación y evaluación», Revista científica de Arquitectura y Urbanismo, 30 (1): 10-17.

Carrión Gútiez, A. (coord.) (2015): Plan Nacional de Paisaje Cultural, Ministerio de Educación, Cultura y Deporte, Madrid.

Cruz Pérez, M.L., ed. (2015): Cien paisajes culturales en España, Ministerio de Educación, Cultura y Deporte, Madrid.

GavazzI, A. (2010): Arquitectura Andina. Formas e historia de los espacios sagrados, Apus Graph, Lima.

Hernández Hernández, M. (2009): «El paisaje como seña de identidad territorial: valorización social y factor de desarrollo, ¿utopía o realidad?», Boletín de la Asociación de Geógrafos Españoles, 49: 169-183.

IZQUIERDO VALLINA, J. (2019): La ciudad agropolitana - la aldea cosmopolita, KRK Ediciones, Oviedo.

Lasanta Martínez, T.; Arnáez Vadillo, J.; Ruiz Flaño, P.; Lana Renault, N. (2013): «Los bancales en las montañas españolas: un paisaje abandonado y un recurso potencial», Boletín de la Asociación de Geógrafos Españoles 63: 301-322. https://doi.org/10.21138/bage.1616

Marco Molina, J.A.; Giménez Font, P.; Padilla Blanco, A. (2018): «Organización tradicional de una ladera de montaña mediterránea: fuentes geohistóricas y trabajo de campo para el análisis de la dinámica del paisaje vegetal» en R.U. Gosálvez Rey, M. C. Díaz Sanz, J.L. García Rayego, M.A. Serrano de la Cruz 
Santos-Olmo y O. Jerez García (coords.), Bosque Mediterráneo y Humedales: Paisaje, Evolución y Conservación. Aportaciones desde la Biogeografía, Almud, Ediciones de Castilla-La Mancha, Ciudad Real: 199-207.

Miguel Rodríguez, A. De (2015): «Paisajes Culturales ¿por qué y cómo?», en Cien Paisajes Culturales en España, Ministerio de Educación, Cultura y Deporte, Madrid: 17-23.

Morales MirAndA, J. (2015): «Interpretación del patrimonio y Museografía. Un romance posible», Museos.es: Revista de la subdirección General de Museos Estatales, 11: 9-24.

Muñoz, F. (2008): Urbanalización. Paisajes comunes, lugares globales, Gustavo Gili, Barcelona.

NoguÉ, J., ed. (2007): La construcción social del paisaje, Biblioteca Nueva, Madrid.

PAlERM SAlAZAR, J.M. (2019): Re-encantar Bancales. Canarias ayer y hoy (siglos XIX, XX y XXI). IV Congreso Mundial ITLA. Territorios de Terrazas y bancales, Gobierno de Canarias, La Gomera.

Parreño Castellano, J.M.; Díaz Hernández, R. (2010): «La ordenación territorial urbanística y de los espacios naturales protegidos y el modelo territorial en la Comunidad Autónoma de Canarias (1982-2009)», Cuadernos Geográficos de la Universidad de Granada, 47 (2): 429-451.

Peters, H.A.; Junchao, S., eds. (2011): First Terraced Landscapes Conference, Paper Collection Editorial Board, Honghe, China.

Rigol Sabio, I. (2004): Módulo 4 Gestión de paisajes culturales en Programa de gestión del patrimonio cultural para el Caribe, UNESCO, La Habana.

Romero-Díaz, A.; De Vente, J.; Díaz-Pereira, E. (2019): «Evaluación de los servicios ecosistémicos proporcionados por las terrazas agrícolas», Pirineos, 174, e043. https:// doi.org/10.3989/pirineos.2019.174003

Romero Martín, L.E.; González Morales, A.; Ramón OjedA, A. (2016): «Towards a new valuation of cultural terraced landscapes: The heritage of terraces in the Canary Islands (Spain)», Annales: Anali za istrske in mediteranske studije-Annali di Studi istriani e mediterranei-Annals for Istrian and Mediterranean Studies. Series Historia et Sociologia, 26: 499-512. https:/ / doi.org/10.19233/ ASHS.2016.31.

SANDOR, J.A. (2006): "Ancient agricultural terraces and soils», en B.P. WARKERTIN, ed., Footprints in the Soil, Elsevier: 505-533.

SAntacana Mestre, J.; Serrat Antolí, N. (2009): «La dimensión patrimonial del paisaje», en J. Busquets y A. CortinA, coord., Gestión del Paisaje, Ariel, Barcelona: 201-220.

SAUER, C.O. (1925): The morphology of landscape, University of California Press, Berkeley.

UnAmuno, M. (2006): Andanzas y visiones españolas, Alianza Editorial, Madrid.

ZÁrAte MARTín, M.A. (2010): «Paisajes culturales urbanos, un legado para conservar», Anales de Geografía de la Universidad Complutense, 30 (2): 187-210.

ZÁrAte MARTín, M.A. (2011): «Paisajes culturales urbanos, entre la conservación y la destrucción», Boletín de la Asociación de Geógrafos Españoles, 57: 175-194.

ZÁrATE MARTín, M.A. (2017): «Paisajes culturales urbanos, oportunidad para la conservación del patrimonio y el turismo sostenible», Estudios Geográficos, 77 (281): 693-728. https:// doi.org/10.3989/estgeogr.201624.

ZoIDO NARANJo, F. (2002): «El paisaje y su utilidad para la ordenación del territorio», en Paisaje y ordenación del territorio, Junta de Andalucía, Sevilla: 15-32. 